\title{
Campos de CONFLitividade Política E MOVIMENTOS SOCIAIS NO EQUADOR DA Revolução Cidadã*
}

\section{Political Conflictivity fields and social movements in ECUADOR'S CITIZEN REVOLUTION}

\author{
Franklin Ramírez Gallegos e Soledad Stoessel
}

\begin{abstract}
Resumo Este artigo estuda a configuração de diversos "campos de conflitividade política” durante o ciclo de governo da Revolução Cidadã, iniciado em 2007. Tal governo, presidido por Rafael Correa, dá início a um processo de mudança política em meio a uma profunda crise de legitimidade da representação política e ao recuo dos movimentos sociais. Esboçada no decorrer da Assembleia Constituinte, a nova agenda pública ativa uma série de episódios contenciosos que evidenciam a capacidade da ação coletiva organizada de construir problemas públicos, apesar de sua debilidade. Nesse sentido, formulam-se questões sobre três campos de conflitividade relacionados a problemas sociais específicos, delineados "de baixo para cima": o déficit de reconhecimento político, a legitimidade da representação social no Estado e as conexões entre buen vivir (bem viver) e desenvolvimento.
\end{abstract}

Palavras-chave campos de conflitividade política; Equador; Revolução Cidadã.

Abstract The aim of this article is to analyze the configuration of diverse "political conflictivity fields" emerged during the governmental cycle known as "Citizen Revolution" started in 2007. This government, headed by Rafael Correa, triggered a political change process in the midst of a deep legitimacy crisis of political representation and of withdrawal of social movements. The new public agenda, outlined during the Constituent Assembly, prompts a set of contentious episodes that reveal the capacity of organized collective action, despite its weakness, to construct

* Artigo traduzido do original, Campos de conflictividad política y movimientos sociales en el Ecuador de la Revolución Ciudadana, por José de Souza Muniz Jr., doutorando em Sociologia pela Universidade de São Paulo (USP) e bolsista da Fundação de Amparo à Pesquisa do Estado de São Paulo (FAPESP).

a Sociólogo, professor e pesquisador do Departamento de Estudios Políticos, Flacso-Equador.

b Socióloga, bolsista de Doutorado no Instituto de Investigaciones en Humanidades y Ciencias Sociales da Universidad Nacional de La Plata - ConICET, Argentina. 
large public problems. In this sense, the paper explores three political conflictivity fields related to specific social problems raised at grassroots level: the deficit of political recognition, the legitimacy of the social representation into the State, and the links between buen vivir (good living) and development.

Keywords political conflictivity fields; Ecuador; Citizen Revolution.

\section{INTRODUÇÃo}

Enquanto distintas perspectivas teóricas estudam a conflitividade, vinculando-a a grandes mudanças políticas, à emergência de ordens normativas e processos de subjetivação política, este texto explora tais vínculos a partir de uma ótica específica: a produtividade da ação coletiva e do conflito para configurar as problemáticas públicas ou "grandes querelas da sociedade" que caracterizam determinados ciclos políticos. Tal abordagem se justifica, entre outras razões, pela paradoxal confluência - no Equador, da Revolução Cidadã (RC) - entre uma crescente conflitividade social e a relativa debilidade das organizações sociais.

De fato, em 2007, tem início no país um processo de mudança, que, em meio à perda de influência dos movimentos sociais, abre a rota pós-neoliberal no Equador (Ramírez Gallegos, 2010a). Diversos aspectos dessa agenda e as lógicas de gestão política que a conduzem são contestados por uma miríade de atores políticos e sociais que desafiam a hegemonia da força governante - a Alianza País (AP). Este texto questiona tais linhas de contestação, enfatizando aqueles conflitos cujo surgimento instala no espaço político determinadas problemáticas públicas com capacidade para alterar as interações socioestatais.

Parte-se do pressuposto de que, em meio à multiplicidade de ações contenciosas, somente algumas configuram o que aqui se denomina "campos de conflitividade política” (CCP). Essa categoria designa os espaços de luta nutridos por conflitos heterogêneos que convergem para problemas públicos específicos e que alcançam efeitos moduladores sobre o conjunto da dinâmica política. Com essa compreensão, o texto examina campos de conflito delineados no Equador, entre 2007 e 2014, em torno da capacidade de certos atores sociais de problematizar publicamente determinadas questões.

Assim, a partir de pesquisas anteriores sobre as tendências do conflito durante o governo da $\mathrm{RC}^{1}$, foram identificados três grandes espaços de luta com relação às seguintes problemáticas: i) déficit de reconhecimento político; ii) legitimidade da

1 Consultar Ramírez Gallegos et. al (2013a; 2013b) e Ramírez Gallegos e Stoessel (2015). 
representação social no Estado; e iii) nexos entre bem viver e desenvolvimento ${ }^{2}$. A disputa em torno dessas questões adquire especial relevância a partir do fim da Assembleia Nacional Constituinte (ANC), em 2008. A transição institucional aberta desde então força uma luta política que gera confrontos do governo tanto com um polo conservador como com alguns segmentos do campo popular. Semelhante correlação de forças ganha corpo durante o segundo governo de Correa (2009-2013) e se estabiliza nos primeiros anos de seu terceiro mandato (2014-2017). A análise de ambos os ciclos de governo permitirá examinar os três campos de conflitividade política anteriormente mencionados.

\section{CONFLITIVIDADE SEM SUJEITO?}

A Alianza País sobe ao poder em meio a uma crise de legitimidade que afeta simultaneamente partidos e movimentos sociais. Tal crise explodiu na revolta de abril de 2005, quando milhares de cidadãos sem muita experiência política ocuparam o espaço público, formaram assembleias e desafiaram o poder, prescindindo do comando de qualquer ator organizado. Apesar de sua radical heterogeneidade, a multitude convergia no repúdio à estrutura de representação e na exigência de uma reforma política imediata: "que se vayan todos" foi seu grito de guerra, durante dez dias (RAmírez GALLEGos, 2005).

O poderoso movimento indígena equatoriano (MIE), que liderou toda a mobilização popular desde 1990, não esteve nas ruas naqueles dias. Sua participação no governo do Coronel Lucio Gutiérrez, cujo desgaste ativou a mobilização de abril, deteriorou a credibilidade das organizações indígenas. Sua hegemonia no campo popular parecia chegar ao fim. Tal perda de influência e o declínio da mobilização social $^{3}$ eram parte dos resultados da inserção do MIE na política institucional.

A revolta se resolveu com a queda de Gutiérrez e o esfacelamento da confiança popular no sistema de representação social e política. No entanto, as demandas da multitude antipartidária ficaram represadas pela recusa dos partidos em abrir qualquer cenário de reforma. Ampliaram-se, então, as opções das agendas de mudança radical. Correa e a AP empunharam essas bandeiras na campanha de 2006. Sua plataforma integrava o Partido Socialista a diversas organizações

2 No marco de uma pesquisa em andamento, determinou-se a existência de outros CCP que se delineiam com a atividade de outro tipo de atores sociais, além dos movimentos.

3 Entre 1999 e 2000, os protestos chegam a seu ápice: registram-se, em média, sessenta e dois conflitos por mês. Após a passagem do Pachakutik - braço eleitoral do MIE - pelo poder (20032005), essa média cai para vinte e cinco. Consultar Revista Ecuador Debate, série 1983-2010, CAAP-Quito. 
camponesas e a pequenos coletivos cidadãos que haviam surgido nos meses anteriores. O restante da esquerda lançou candidaturas próprias e teve seus piores resultados, desde a volta da democracia (1979).

Após enfrentar, no segundo turno, o empresário da produção de banana Álvaro Noboa, Correa se elegeu com 54\% dos votos. Deixar para trás "a longa e triste noite neoliberal" e desmontar a "partidocracia" foram suas grandes propostas de campanha. Logo que foi empossada, e em sintonia com a "agenda de abril", a AP convocou uma consulta popular para instalar a Assembleia Nacional Constituinte: $82 \%$ da população se posicionou a favor da proposta. A partir de então, o voto popular seria o principal sustentáculo para a ascensão de um presidente com vocação transformadora que governava sem bancada parlamentar ${ }^{4}$ e em meio à fragilidade do tecido associativo.

A eleição dos constituintes significou outra derrota das forças do establishment neoliberal: a AP obteve 80 dos 130 assentos em disputa, e o restante das forças de esquerda ${ }^{5}$ obteve quase $10 \%$. O oficialismo incluiu a representação de várias organizações populares. A AP adquiria, assim, o perfil de uma coalizão de frações em que coexistiam setores de centro, velhas e novas militâncias de esquerda, segmentos dos movimentos sociais (camponeses, indígenas, ecologistas e jovens), cidadãos sem muita experiência política e políticos oportunistas de longa trajetória.

Em um contexto de recuo da mobilização, a nova Carta Magna ampliou o espectro de direitos cidadãos, inovou em políticas ambientais, estendeu as instituições de participação popular, consagrou a plurinacionalidade do Estado e, na contramão do Consenso de Washington, voltou a atribuir ao Estado o papel de coordenador social e proibiu a privatização de recursos públicos. Não foram poucas as disputas entre o poder executivo, a AP e certos movimentos, mas, ainda assim, a ANC conseguiu gerar uma fluida dinâmica de interlocução entre as forças progressistas. Tal convergência se plasmou na Consulta Popular que aprovou a Carta Magna com 63\% dos votos.

Em 2009, foram realizadas as primeiras eleições gerais com a vigência da nova Constituição. Correa foi eleito, em um fato sem precedentes: no primeiro turno e com 52,9\% dos votos válidos. Começou, então, o trânsito pós-constituinte: o momento de institucionalização dos princípios constitucionais em códigos espe-

4 A AP não lançou candidaturas ao Congresso para ressaltar sua estratégia antissistêmica e desgastar ainda mais a confiança no Parlamento.

5 Esse bloco era integrado pela socialdemocracia, pelo Movimento de Unidade Plurinacional Pachakutik (MupP) e pelo Movimiento Popular Democrático (MPD, partido filomaoísta que controlava os grêmios da educação pública). 
cíficos, leis orgânicas e políticas públicas. Tal momento alterou o terreno da luta política, porque, em meio ao enorme apoio popular ao presidente, a AP tendeu a subestimar a contribuição das organizações sociais no processo político. Elas se ressentiam desse distanciamento e exigiam participação real. O "bloco pela mudança” se fragmentou. O mal-estar indígena era particularmente visível. A partir de então, a RC deveria fazer frente tanto aos embates da direita e dos grupos de poder que conduziram o país a um conturbado processo de desmantelamento estatal e liberalização econômica como à contestação de organizações e pequenos partidos de esquerda. A decomposição articuladora da AP brecou a transição institucional e estimulou a reativação do conflito (Gráfico 1), apesar da fragilidade do movimento social.

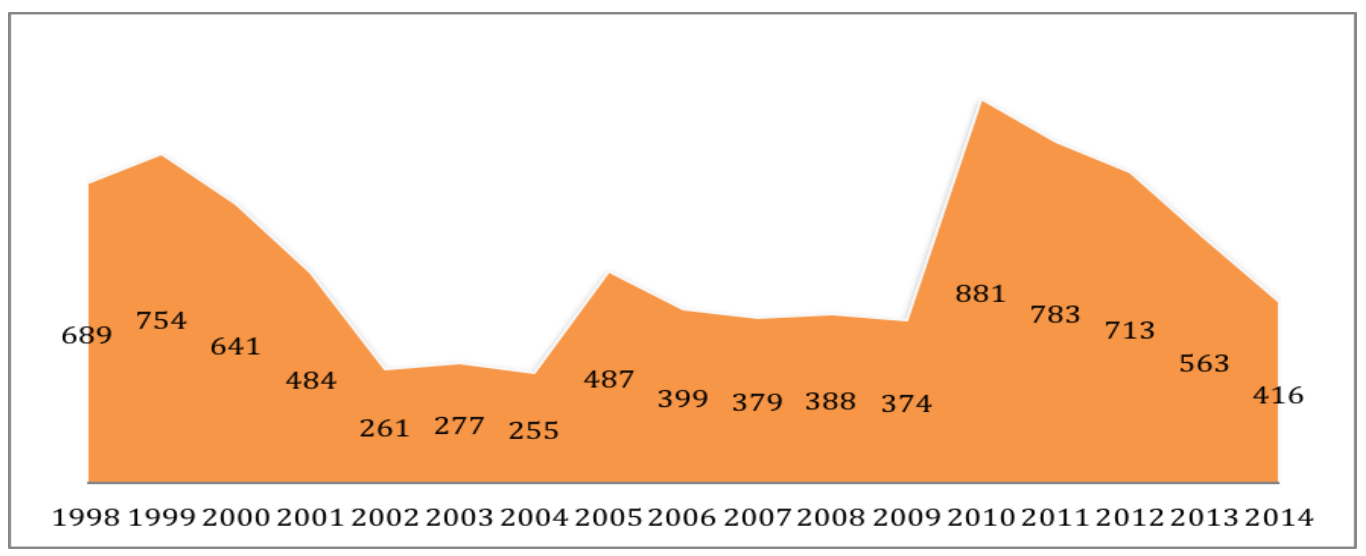

Gráfico 1. Frequência do conflito sociopolítico 1998-2014. Fonte: CAAP. Elaboração própria.

A paradoxal confluência entre o dinamismo do conflito $^{6}$ e a fragilidade da ação organizada - conflitividade sem sujeito? - aparece como uma característica marcante do atual momento político. Diante dessa cena, convém interrogar sobre os traços da mobilização coletiva em ciclos de recuo. Um ângulo particularmente frutífero para esse questionamento é imbricar o estudo do conflito político à emergência de problemas públicos. A capacidade de problematização é, de fato, uma qualidade distinta da mobilização coletiva, mesmo em circunstâncias nas quais os atores sociais encontram dificuldades para incidir sobre o processo democrático. Esse seria um modo de ler, hoje em dia, a incidência da luta social na vida política do Equador. Nesse sentido, como dar conta da emergência de uma pluralidade de problemas públicos com capacidade para interpelar o sistema político em um

6 Entre 2010 e 2013, a frequência do conflito chegou a ritmos superiores ao agitado final da década de 1990, momento em que o país entrou em sua pior crise econômica e viu-se obrigado a dolarizar a economia. 
contexto de involução de diversas dinâmicas de ação coletiva? Para responder a essa questão, objeto central do artigo, convém construir um dispositivo analítico que verifique as conexões entre mobilização coletiva, conflito político e problemas públicos. A noção de CCP, explicada a seguir, busca dar conta de tais conexões.

\section{A ABORDAGEM DOS CCP}

Embora exista uma prolífica literatura voltada ao estudo da ação coletiva, por um lado, e aos problemas públicos, por outro, poucos trabalhos abordam especificamente a articulação entre ambos. As contribuições de Neveu (2000) são uma exceção. Para esse autor, os movimentos sociais podem ser entendidos a partir de sua contribuição "para a definição dos problemas sobre os quais se espera uma ação estatal [...], a inscrever na ordem do dia debates e intervenções públicas" (NEveu, 2000, p. 30). Isso está atado a uma dupla operação: pela via das políticas estatais, estabilizam-se espaços e procedimentos de negociação que marcam o terreno de ação para os movimentos; por outro lado, eles têm a capacidade de operar a partir das "arenas de conflito social”. A abordagem dos CCP dialoga com tal perspectiva, porque vislumbra o papel fundamental da conflitividade e dos movimentos no processo de instituição de uma multiplicidade de "questões" arenas socioestatais (o que não exclui a eficácia do sistema político em posicionar problemas sociais).

Situar o conflito na linha de definição das "questões" exige, de antemão, fazer referência a um de seus atributos fundamentais: sua dimensão pública (GuSFIELD, 2014). A encenação do conflito, pela via de distintos repertórios, visibiliza agentes e insatisfações sociais que, de outra forma, teriam menos probabilidade de ganhar eco social. Desse modo, para que uma situação comece a ser considerada problemática, é primordial que seja reconhecida como tal por certos atores e que eles se mobilizem para mostrar que tal é o caso. Ao fazê-lo, procuram a mais ampla aceitação na esfera pública (SchillaGi, 2011).

Além disso, na medida em que o conflito encarna identidades coletivas, marcos ideológicos e reivindicações comuns sobre alguma situação percebida como preocupante - de modo mais ou menos compartilhado e sustentado no tempo -, também se inscreve nos processos de construção de problemas sociais. Tal dinâmica não impulsiona os episódios de conflitividade somente na direção das instituições que

7 O’Donnell e Oszlak (1987) usam a noção de "questões" no mesmo sentido que aqui se atribui à ideia de "problemas públicos". 
os atores consideram responsáveis por uma situação malfadada, mas também no sentido da própria definição do problema. Em geral, o modo como determinada situação se fixa como problemática é objeto de discrepâncias públicas, no interior ou entre organizações e coletivos que podem perseguir finalidades semelhantes ou ter insatisfações equivalentes.

Nesse sentido, não parece descabido situar o conflito como parte do duplo exercício que acompanha a instauração de problemas sociais no espaço político: a definição de uma situação como problemática (problematização) e a configuração de atores e públicos afetados por tal situação (publicização). Os três processos conflitividade, problematização e publicização - possuem, de toda forma, uma natureza propriamente política, na medida em que se instalam como parte dos "modos de regulação constitutivos de uma ordem social passível de crítica e modificação" (CEFAÏ, 2014, p. 17).

A emergência de problemas sociais está associada, então, à irrupção pública de atores que definem e tornam audíveis situações que perturbam seus interesses, identidades ou contextos de experiência. Dessa maneira, a expressão de demandas coletivas, públicas e visíveis (DCPV) ${ }^{8}$ se coloca como uma das atividades práticas que, de modo irredutível, moldam a construção das problemáticas públicas.

Pois bem, os conflitos com capacidade para irradiar problemas não apenas têm um atributo de publicidade e um caráter coletivo, mas também implicam efeitos $e$ qualidades políticas específicos, ligados a, pelo menos, duas questões: a) chamar a atenção de outros atores ou públicos (grupos, a priori, alheios às reivindicações dos mobilizados); e b) reacomodar o campo da luta política pela via da interpelação ao sistema político e da intervenção estatal.

Tal proposição reconhece que nem todo episódio contencioso é condição sine qua non para a elaboração de problemáticas públicas, mas, ao mesmo tempo, afirma que no conflito reside uma potência da qual carecem outros fenômenos políticos: ativar, de forma simultânea, diversos efeitos no plano da ação coletiva, das relações de poder, do sistema político, em suma, do conjunto de interações socioestatais. Assim, a dupla produtividade do conflito reside no fato de que, por meio dele, os públicos emergem e, ao mesmo tempo, reverberam as demandas sociais que definem o terreno da contenda política. Um nível e outro estão condicionados pelas características do campo de forças que demarca o confronto.

De fato, embora o conflito político expresse (pelo menos) o grau zero da incubação de problemas públicos, o encadeamento analítico entre ambas as dimensões

8 Recorre-se, aqui, à noção tillyana de conflito político (Tılly, 1998, p. 12-13). 
só adquire pertinência em referência ao entorno político em que se inscreve e que o torna possível. A relevância heurística desse nexo é dada, portanto, por sua capacidade de informar sobre a relação entre o caráter do ciclo político e a orientação da conflitividade forjada em seu bojo: os processos políticos levam a marca dos antagonismos que o circundam, e estes somente cobram sentido no entorno específico que os institui.

Embora os ciclos políticos outorguem sentido à relação entre conflitividade e problemas públicos, a detecção de um CCP requer prestar atenção no modo como conflitos distintos se entrelaçam. De fato, ainda que se possa afirmar que um episódio de mobilização está em condição de definir como problemática uma situação específica e, portanto, de incubar problemáticas sociais (Esquema 1), a abordagem dos CCP postula que é na confluência de diversos conflitos - pelo menos dois - que cabe rastrear a potencial emergência de "querelas de sociedade" que marcam a fogo o processo político que os engloba.

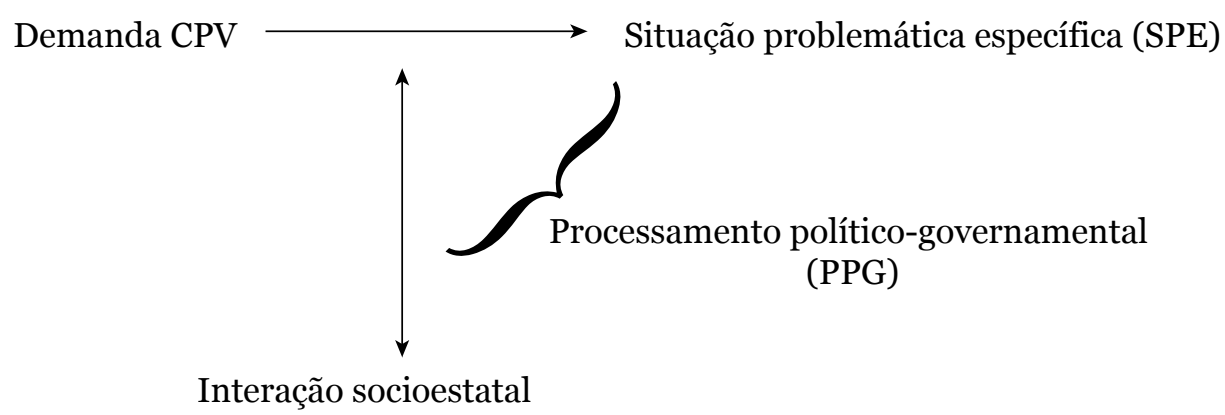

Esquema 1. Conflito político.

O recurso à noção de campos como espaços de luta dá conta precisamente da convergência entre conflitos: ainda que cada um deles designe situações problemáticas específicas e expresse certa incubação de um problema social, é na simultaneidade de sua emergência que se pode rastrear indícios de problemáticas comuns contidas em tais lutas. Um CCP designa esse conjunto de articulações (Esquema 2).

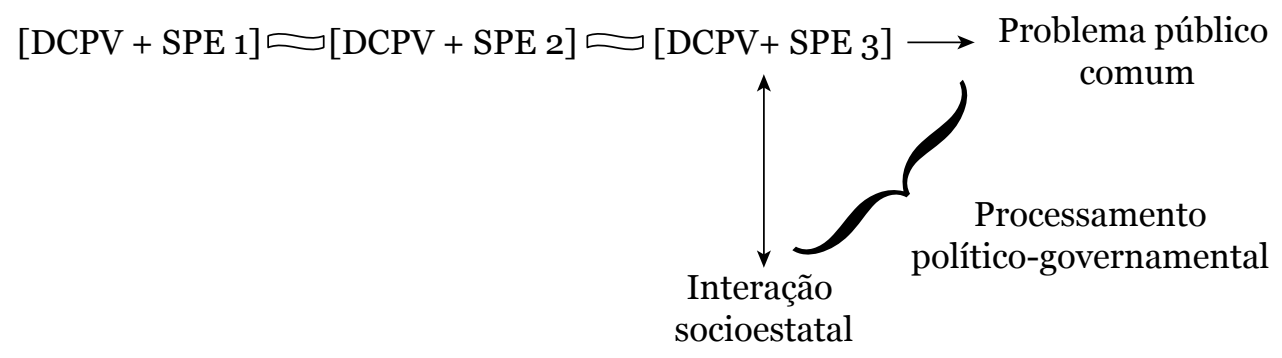

Esquema 2. Campo de conflitividade política. 
Como se pode notar, neste ponto se introduz um deslocamento conceitual na terminologia sobre os problemas públicos: usa-se a locução "situação problemática específica” para designar a problemática em gestação contida em cada conflito político (Esquema 1) e se alude à ideia de "problemática comum" (querela de sociedade) para aludir às questões que emergem da confluência de conflitos que fazem referência a situações problemáticas similares (Esquema 2).

Com essa diferenciação, coloca-se o núcleo teórico para o tema que quer ser captado pela abordagem dos CCP: a pergunta pelo movimento de ascensão ao comum (generalização) expresso - ainda que nem sempre de modo explícito - em cada episódio de conflitividade. Uma preocupação semelhante também forma parte do corpus de certa Sociologia dos problemas públicos, preocupada com as operações de generalização que os próprios atores põem em jogo para conectar um conflito particular com uma situação universal (Gusfield, 2014; CEFAI; TrOM, 2010). $\mathrm{Na}$ abordagem aqui utilizada, o movimento em direção ao comum é apreendido, relacionando conflitos políticos heterogêneos que se manifestam em meio a oscilações da luta política e denotam objetos similares de contestação. Nesse sentido, os problemas comuns aparecem como construtos analíticos forjados a partir de situações definidas (pela via do conflito) como prejudiciais para um grupo, mas que também pressupõem uma preocupação pelo bem público ou uma alusão a assuntos de ordem geral.

Os campos de conflitividade política se definem, então, como espaços de luta estruturados a partir de uma diversidade de conflitos políticos que se conectam entre si por sua referência a uma problemática comum. Tal característica lhes confere uma alta capacidade (des)instituinte sobre as interações socioestatais e o conjunto da dinâmica política. Trata-se, em suma, de uma ficção analítica que permite examinar os registros do universal (problemas comuns) encapsulados no momento do conflito (manifestação de problemas específicos), ao mesmo tempo em que os coloca no horizonte espaço-temporal do processo político que os instaura.

\section{RUMO À CONFIGURAÇÃO DE TRÊS CCP}

Esta parte do artigo caracteriza os espaços de luta política que emergem durante o governo da $\mathrm{RC}$, com relação a três problemáticas que atravessam conflitos específicos: déficit de reconhecimento político; legitimidade da representação social no Estado; e nexos entre desenvolvimento e bem viver na transição pós-neoliberal. Para determinar a instauração desses campos, consideram-se quatro critérios, derivados da abordagem analítica esboçada anteriormente: a) uma "problemática 
comum" provém da convergência de, pelo menos, dois conflitos políticos; b) eles são protagonizados por atores heterogêneos, de forma mais ou menos prolongada no tempo; c) tais conflitos aludem a uma mesma situação problemática; e d) os CCP têm consequências específicas sobre o conjunto da luta política.

a) Lutas por reconhecimento político

A implantação da liderança de Correa transcorreu no sentido inverso à sua capacidade de reconhecer o valor das identidades coletivas e a contribuição das organizações sociais ao jogo democrático. Se, em 2006, quando lançou sua candidatura presencial, o outsider e jovem economista buscou a participação do movimento indígena em sua fórmula eleitoral - algo a que o movimento resistiu -, anos mais tarde, quando a AP já era uma força nacional e Correa era um presidente de alta aprovação popular, praticamente não promove interações políticas densas com atores coletivos mais ou menos autônomos. Assim, exceto em conjunturas críticas (mobilizações e eventos eleitorais), o presidente instalou uma lógica que não somente prescinde da interlocução democrática com os setores organizados, mas também tende a desdenhar as trajetórias políticas de certos atores. Tal estilo de relacionamento político, que reduz os espaços de debate socioestatal, foi reprovado de imeditado "desde abajo".

De fato, forças sociais heterogêneas definiram o que, em princípio, parecia um impasse político como uma situação problemática para a afirmação de suas identidades coletivas, de seu trabalho organizativo e de sua interação com as agências estatais. Tomaram distância, então, desse modo de gerir a política. Antes de mais nada, as organizações reclamam da falta de respeito e do déficit de reconhecimento político da liderança presidencial com relação a determinadas dinâmicas de ação coletiva. Trata-se da explosão exacerbada de identidades em contextos de menosprezo sistemático do poder por seu papel no processo democrático.

A conquista de reconhecimento é constitutiva dos sujeitos, na medida em que a afirmação pública do valor social de sua identidade forma parte de seu processo de autonomização. A virtude das ações afirmadoras reside, então, no fato de que "permitem ao destinatário identificar-se com suas qualidades [...], longe de representar uma mera ideologia, o reconhecimento configura as condições intersubjetivas da capacidade de realizar autonomamente seus próprios objetivos vitais" (HoNNETH, 2006, p. 135). Não em vão, as lutas por reconhecimento se colocam no 
centro da autoformação dos atores, e sua imersão, na esfera pública9 ${ }^{9}$ Esse seria o tom do mal-estar de certos segmentos do campo organizativo equatoriano. Suas demandas sobre isso se mantiveram estáveis durante o ciclo analisado. De modo geral, procuram estima e respeito ao mandatário da nação. A falta de reconhecimento aparece, assim, como uma problemática comum aos conflitos que delineiam o primeiro CCP aqui estudado. Dois episódios de protesto permitem entender com clareza o que se pôs em jogo nesse espaço de luta:

1. Desde seu primeiro levante, em 1990, o MIE conseguiu "sentar-se" para negociar com todos os governos vigentes, depois de contundentes mobilizações. $\mathrm{O}$ sujeito indígena se colocava, assim, como interlocutor legítimo do poder público. Esse reconhecimento se expressou, além disso, por meio da inclusão de representantes indígenas em diversas agências governamentais e do controle quase corporativo, pela ConAIE (Confederação de Nacionalidades Indígenas do Equador) de determinados setores da política pública de interesse para o movimento. Desse modo, conflito, negociação e representação estabilizavam o fluxo de reconhecimento político que o movimento havia montado a partir da luta extraparlamentar. Ainda que a influência do MIE tenha diminuído, desde sua passagem pelo poder (2002-2003), com a RC, tal debilidade se entrelaça com o déficit de reconhecimento governamental e com a escassa interlocução entre ambos os atores.

Durante a Constituinte, entretanto, o Pachakutik formou parte da coalizão oficial e conseguiu incorporar várias de suas principais demandas - o caráter plurinacional do Estado, por exemplo - na Carta Magna. Tal incidência diminuiu no período pós-constituinte, no qual o oficialismo esboçou um exercício político de decisão. Além de algumas diferenças programáticas na orientação do processo de mudança, ele amplificou as demandas do MIE por real participação política e exacerbou vários episódios de tensão com o governo da AP.

Em 2009, a ConAIE se mobilizou contra a Lei de Mineração e a Lei de Recursos Hídricos ${ }^{10}$, que deviam ser aprovadas, com urgência, na Assembleia. As organizações indígenas e seus aliados reclamaram da falta de "consulta prévia" às comunidades sobre o conteúdo das leis (Chávez, 2010). Apenas quando o protesto alcançou altos níveis de violência, o governo ativou mesas de negociação encabeçadas pelo mesmo presidente, tal como havia acontecido durante os anos 1990. Nos diálogos, uma das principais queixas indígenas a Correa foi sua "falta de respeito"

9 Isso é válido mesmo se se assumem as críticas à política do reconhecimento como mecanismo ideológico que constrói um tipo de relação dos atores com eles próprios, que, por sua vez, os põem em conformidade com as relações de dominação existentes (HoNNETH, 2006).

10 Adiante, retomar-se-á a análise de ambas as leis. 
para com o movimento. Em uma dessas sessões, transmitida ao vivo pela televisão pública, um alto dirigente da ConAIE, Humberto Cholango, instou o presidente a desculpar-se com o movimento por tê-los chamado de "loucos"11.

As mesas de negociação entraram em crise rapidamente. Para a ConAIE, Correa não levou a sério o processo nem acolheu suas principais demandas. Para o governo, a liderança indígena se entrincheirou em uma agenda parcial ("indigenista”) e ignorou a orientação universal e popular das novas políticas públicas. Os vínculos entre o presidente e a ConAIE se deterioraram a ponto de convertê-los em nítidos adversários ${ }^{12}$.

2. O segundo "conflito por reconhecimento" foi protagonizado pela União Nacional de Educadores (UNE), o principal grêmio docente do país. Até 2009, esse sindicato e seu partido afim - o MPD - operaram como aliados da RC, mas, depois disso, se distanciaram da linha oficial. A ruptura começou com a discussão das reformas à Lei da Carreira Docente e Escalão do Magistério Nacional e da Lei Orgânica de Educação Intercultural. Nesses debates, o presidente arremeteu contra o corporativismo gremial e desacreditou de sua legitimidade democrática. Os docentes perceberam esse discurso como uma ofensa a sua identidade coletiva.

A reforma educativa estava orientada a ordenar a dispersão institucional e desmontar a captura corporativa da política educativa por parte da UNE (Posso, 2013). Para o governo, tal captura havia contribuído para afundar a educação pública na "mediocridade" e na "ineficiência"13. Assim, as mudanças propostas redundariam em diminuição do poder docente, democratização do sistema educativo e, sobretudo, busca de aumento da qualidade da educação nacional. Nos anos 1990, o poderoso grêmio docente resistiu a todas as tentativas de tirar-lhe de seu lugar, no sistema educativo.

Dois aspectos da reforma suscitaram especial controvérsia: as mudanças nos processos de seleção e promoção docente - nos quais a UNE havia alcançado enorme influência, há décadas - e nas bonificações adicionais que complementavam o salário mensal dos professores. O projeto proposto pelo governo eliminava o conceito de "antiguidade docente" e atribuía ao Ministério de Educação a tarefa de ministrar as provas aos docentes como mecanismo de avaliação e progressão

11 Consultar El Universo, 11 out. 2009. Disponível em: <http://www.eluniverso. com/2009/10/11/1/1355/humberto-cholango-en-gobierno-hay-grupos-quieren-haya-dialogos. html >. Acesso em: 14 de abril de 2015.

12 Em 2010, a ConAIE se manifestou contrária à cúpula da Alianza Bolivariana de los Pueblos de Nuestra América (AlbA), que contava com a presença de H. Chávez e E. Morales. O governo considerou essa ação uma provocação do MIE.

13 Declarações de Correa na concentração "Unidos contra la mediocridad" (29 maio 2009) e em sua visita a colégios em meio à greve docente (22 de setembro de 2009). 
com base no mérito. A resposta gremial foi rechaçar a avaliação. Além disso, suprimiu-se o bônus associado à chamada "aposentadoria adicional" dos sindicalizados e, em seu lugar, aumentou-se o salário para equipará-lo ao do restante dos servidores públicos. De acordo com o sindicato, essa medida não considerava as particularidades profissionais dos professores.

Tendo em vista tais medidas, o grêmio convocou uma paralisação das atividades (setembro de 2009) que durou um mês e, a contragosto de Correa, forçou o governo a negociar. Nas palavras de Mariana Pallasco, presidenta do grêmio naquela ocasião:

A greve não foi por aumento salarial; desta vez, a paralisação foi por dignidade, para acabar com os maus-tratos, para acabar com a desqualificação. [...] o trabalho docente não é revalorizado apenas com dinheiro. [...] estigmatizaram o professor [...] na rua, se sabiam que alguém era professor, lhe diziam "professor vagabundo, vá ser avaliado” (apud Posso, 2013, p. 124).

A percepção de afronta é nítida: busca-se reverter um estigma para cuja propagação as ofensas presidenciais tinham contribuído. Economia moral (prestígio docente) e economia política (salários) se articulam, também, na defesa da "antiguidade laboral" como mecanismo de gratificação econômica e direito que forja a identidade coletiva.

Então, a disputa por reconhecimento político como problemática comum a diversos episódios de contenda deve se situar, para além dos estilos de gestão do mandatário, como parte do caráter da luta aberta no meio de um ciclo de mudanças profundas. Assim, por um lado, a balança do poder extremamente favorável à RC supôs a relativa perda de eficácia dos padrões usuais de pressão política - conflito, negociação e acordo - com os quais distintos agentes sociais haviam estabelecido nexos com governos anteriores. Por outro lado, a concepção revolucionário-jacobina da política, na visão da AP, tornou suspeita de particularismo qualquer dinâmica coletiva que tendesse a forçar o sentido das decisões públicas legitimadas pelas urnas. Por fim, as amplas vitórias eleitorais do governo lhe outorgam uma legitimidade de origem tal que o voto popular foi conceituado como consenso integral em torno do projeto de mudança.

No entanto, a integralidade desse consenso é desafiada pelo modo como diferentes atores sociais elaboram de forma similar seu mal-estar público com relação a situações que minam o valor de suas identidades coletivas e subestimam seu lugar no processo democrático. Implantam, assim, um problema público que questiona 
a crença presidencial de que a volumosa política redistributiva de seu governo contém, por si própria, a dimensão de reconhecimento moral e político com que os sujeitos conseguem se inscrever, de modo integral, na comunidade política. Não obstante, sem reconhecimento não há interlocução democrática possível e, sem esta, debilita-se o conteúdo participativo do jogo democrático.

b) Batalhas pela representação no Estado

Os dois primeiros governos da RC estão atados à conflituosa dinâmica do retorno do Estado e a seu reposicionamento como eixo da coordenação social. À diferença do Consenso de Washington, que debilitou a ação estatal e diluiu a preocupação com relação a seu papel na afirmação do bem comum, o processo inaugurado em 2007 dotou o Estado de capacidades para afirmar sua soberania, planejar o desenvolvimento, governar os mercados e redistribuir a riqueza.

Consolidar esse cenário pressupôs, entre outros fatores, uma agressiva reforma institucional que assegurasse o comando do poder civil sobre a política pública. Isso minou as bases de distintos pactos corporativos que, em seu momento, conferiram influência e representação estatal a atores sociais heterogêneos. Para estes últimos - grêmios empresariais ou populares, atores civis ou militares, organismos burocráticos ou não governamentais -, tais reformas punham em risco conquistas prévias: representação, poder de decisão e/ou acesso a benefícios particulares. Um verdadeiro litígio democrático emerge dessa batalha pela reforma institucional: a disputa pela legitimidade da representação e pelo peso do poder corporativo no Estado (OsPina, 2011; RAmírez GALlEgos, 2012). Tal é a problemática comum a distintos episódios contenciosos que configuram o segundo CCP examinado neste texto. A seguir, são abordados alguns desses episódios:

1. A reforma institucional priorizou a regulação das agências estatais em cujos corpos colegiados estavam representados apenas determinados interesses. Assim, quando não os eliminou, inseriu uma cota de representação pública, sobretudo do Executivo, em sua composição.

O governo pôs ênfase em diminuir o poder de fixar agendas dos órgãos colegiados nos quais as frações do capital privado estavam sobrerrepresentadas. Tratava-se de evitar a ingerência de seus grêmios, em todo o conselho de política pública em que tivessem voz e voto. Tal deslocamento foi particularmente sensível no âmbito bancário, no da política comercial, nos diretórios das empresas públicas e no setor das comunicações. Assim, por exemplo, no Conselho de Comércio Exterior e Investimentos, suprimiu-se a representação do setor privado - que ocupava 
45\% do órgão colegiado - e criou-se um órgão composto totalmente por delegados do governo central. A reprovação do mundo empresarial não tardou em aparecer.

Pois bem, as tentativas de reduzir o peso dos interesses corporativos não se voltaram apenas contra os grandes grupos econômicos. O governo também procurou desarticular determinados acordos segundo os quais organizações populares e grêmios públicos haviam conquistado capacidade decisória e/ou poder de veto sobre campos específicos da política pública. O confronto entre o governo e o movimento indígena com relação à Lei de Águas ilustra cabalmente essa problemática.

Assim, embora durante o debate legislativo o governo e o movimento tivessem coincidido quanto à necessidade de reconstruir a autoridade pública do setor hídrico - desmantelada pelos neoliberais em 1994 -, discordaram com relação à composição da entidade que regulamenta o setor. A ConAIE propôs que essa autoridade fosse um Conselho Intercultural e Plurinacional com delegados indígenas, usuários do sistema de irrigação, consumidores, movimentos e uma representação minoritária do governo. Para este, essa figura outorgava a tais setores atribuições não contempladas na Constituição e relegava o poder público a um plano secundário. Por isso, sua proposta previa que o presidente nomeasse uma "Autoridade Única da Água" (instância do Poder Executivo) e incluísse o Conselho Plurinacional somente como organismo consultivo, com composição paritária do governo e das comunidades.

Em meio às crescentes mobilizações e aos desacordos, a Lei de Águas não pôde ser aprovada, senão em 2014, ou seja, cinco anos depois do estipulado na Constituição e somente quando a AP, já em seu terceiro mandato, passou a ocupar mais de dois terços da bancada na Assembleia. Ainda assim, durante os debates finais desta, Jorge Herrera, presidente da ConAIE, argumentou que, embora a nova lei incluísse avanços substantivos com relação àquilo que havia sido debatido havia quatro anos, o problema de fundo persistia: "estamos de acordo que seja o Estado a autoridade (da água), mas nós (pela ConAIE) também somos Estado"14. Mais que uma reprovação do retorno estatal, e em que pese o espírito autonomista que diversos estratos intelectuais atribuem aos movimentos indígenas, tais organizações reivindicaram a presença de seus interesses no interior das instituições públicas. Em sua perspectiva, a vocação universalista da ação estatal está atada à

14 Consultar Diario El Comercio, 24 jun. 2014. Disponível em: <http://www.elcomercio.com/ actualidad/asamblea-aprobo-ley-aguas-ecuador.html>. Acesso em: 10 de abril de 2015. 
participação social em seu seio, e não se garante apenas pela eleição popular dos representantes, como argumenta Correa.

Uma tensão semelhante ocorreu a propósito da nova lei universitária, que modificou as estruturas de representação do ensino superior. A lei criou dois organismos (o Conselho de Educação Superior e a Agência Nacional de Credenciamento e Garantia da Qualidade), compostos por representantes do Poder Executivo e por atores do ensino superior. Esses últimos, em vez de representar instituições específicas, são selecionados em função das distintas áreas de conhecimento (Ramírez Gallegos; Minteguiaga, 2010).

Além disso, sua escolha depende de um concurso público de mérito e arguição. Anteriormente, os reitores de universidades públicas e privadas formavam parte automaticamente da máxima instância de regulação do sistema, da qual estava excluído o poder público. Nesse sentido, o Estado equatoriano carecia de uma política universitária, e esta dependia da “corporação dos reitores”. Embora a normativa tenha decretado o cogoverno e criado uma assembleia universitária (composta por reitores, professores, estudantes e trabalhadores), foi percebida como um atentado à autonomia do campo. Diversas mobilizações promovidas por reitores e proprietários das universidades puseram em suspenso a aprovação dessa lei.

2. O motim da força pública de 30 de setembro de 2010 (30-S) aparece como outra das grandes "batalhas pela representação no Estado" no ciclo analisado. Naquele dia, o país amanheceu com a notícia de que a polícia nacional havia se insurgido contra a Lei Orgânica de Serviço Público (Loser), que estava sendo debatida na Assembleia ${ }^{15}$. Em termos gerais, tal conjunto de normas procurava "recuperar a institucionalidade estatal" (LOSEP, 2010) e impregnar a função pública de eficiência, racionalidade e espírito democrático. A lei estava orientada a regular os regimes laborais de uma pluralidade de âmbitos do setor público (incluindo os policiais). O parlamento contemplou, então, a participação de uma multiplicidade de organizações e grêmios no debate legislativo, com a realização de fóruns em diversas cidades do país (agosto de 2009).

15 A partir do motim policial, surgiu uma série de ações contenciosas - tomada do aeroporto e de distintas repartições públicas, bloqueio da Assembleia, mobilizações em outras cidades, saques - por parte de servidores públicos, estudantes e docentes afinados ao MPD, certas organizações indígenas, assim como de cidadãos e militantes da AP que se mobilizaram para apoiar o regime democrático. 
Não obstante, à medida que se tornava evidente a orientação que o Executivo queria dar a certos aspectos da lei, desenrolou-se uma série de ações contenciosas (mobilizações, greves, comunicados, etc.), protagonizadas, fundamentalmente, por grêmios de servidores públicos: servidores da Função Judicial (11 de setembro de 2010), a Federação de Estudantes Universitários do Equador (22 de setembro), a Federação Nacional de Servidores Públicos, trabalhadores da saúde e do serviço exterior, funcionários do Ministério da Defesa (23 de setembro) e outros atores políticos.

O confronto entre esses atores e o governo girou ao redor de três temas presentes na lei: o mecanismo da "compra de demissão obrigatória", a supressão dos estatutos laborais de cada setor e a eliminação das condecorações e bonificações adicionais. De fato, a norma buscava qualidade e eficiência na provisão de serviços públicos. Isso dependia da abertura de vagas ("compra de demissões") para que os mais jovens pudessem ingressar na função pública por meio de concurso de méritos e arguição. Além disso, a LosEP procurava equiparar salários e regimes laborais para todos os funcionários, porque, durante o período neoliberal, multiplicaram-se os entes estatais que, sob o argumento de autonomia organizacional, criaram seus próprios regimes de pessoal e remunerações.

Nesse mesmo sentido, a normativa eliminava qualquer estímulo e bonificação adicional - prêmios, bônus, medalhas, etc. - à estrutura salarial de base de todos os funcionários. Ainda que o governo nacional tenha garantido que compensaria a eliminação de tais benefícios com o aumento do salário e o pagamento de horas extras, isso foi considerado por diversos segmentos da burocracia um desconhecimento de seus direitos "adquiridos e conquistados durante anos de luta e trabalho" (Stoessel, 2013a). Para o governo, em contrapartida, favorecer garantias especiais incentivava a apropriação particularista do Estado e impedia a universalização de direitos. A oposição legislativa criticava o governo por tal visão "universalista”: “o presidente se equivoca, quer tratar todos os servidores de maneira igual. Sempre haverá particularidades, um professor não é o mesmo que um policial, não pode existir equidade entre os servidores públicos, precisamente porque eles não são iguais" (Lourdes Tibán, assembleista pelo Pachakutik, citada em: STOESSEL, 2013b).

Nesse contexto, em 29 de setembro, publica-se o veto presidencial ao projeto da LoSEP que, tendo sido aprovado por maioria parlamentar, ratificava a eliminação dos benefícios especiais para os distintos setores públicos. Esse foi o fator que terminou por ativar a revolta policial no dia seguinte. Para os fardados, a supressão das medalhas e condecorações (pelo "mérito em combate") constituía uma afronta à sua identidade institucional. O motim gerou uma espiral de violência 
sem precedentes (oito mortos e mais de duzentos e cinquenta feridos), que pôs em risco a institucionalidade democrática.

Em suma, se ao longo do ciclo neoliberal a resistência social se ativou contra as tentativas de privatização e diminuição do Estado, no ciclo vigente, a disputa gira ao redor da influência corporativa e da legitimidade da representação social no aparelho público. A vontade governamental de desativar acordos corporativos e "medidas especiais" deixou ver o peso e a capacidade de reação, dos interesses representados dentro das instituições públicas. Mais que confrontar o retorno do Estado, esses setores lutam para preservar o lugar que já haviam conquistado dentro dele. Dessa maneira, tomam distância do universalismo do governo e de sua tendência de colocar em um mesmo plano político o cidadão abstrato e os atores organizados. Correa vê nessas demandas a expressão do particularismo das lideranças sociais e acirra seu déficit de representatividade.

c) Querelas pelo bem viver e pelo desenvolvimento

O primeiro Plano Nacional de Desenvolvimento (2007) do governo equatoriano incorporou um capítulo que discutia a noção de desenvolvimento. Postulava-se, assim, a necessidade de defini-lo de um modo "que não subscreva como único objetivo a busca do crescimento econômico" e se propunha uma concepção alternativa que incluía três questões: melhorar o bem-estar da população, incentivar dinâmicas econômicas que não comprometam a sustentabilidade ambiental e respeitar a diversidade cultural. Em torno desses elementos, o desenvolvimento foi redefinido como "a consecução do bem viver de todos e todas, em paz e harmonia com a natureza e o prolongamento indefinido das culturas humanas" (SENPLADES, 2007-2010, p. 51). Tal formulação se apresentava, ao mesmo tempo, como uma alternativa de e para o desenvolvimento.

Em seguida, a Carta Magna radicalizou os sentidos do bem viver e impregnou o conjunto do processo político com sua marca. Tal operação consistiu em ancorar o bem viver nas formas de vida do mundo indígena, assim como nas lutas pela plurinacionalidade e pela interculturalidade, desatadas no país desde os anos 1980. O bem viver, ou sumak kawsay, articulava as críticas ecológicas ao desenvolvimento às demandas por reconhecimento da diferença. Embora este não se contradissesse à consecução do bem-estar, parecia redefini-lo em um sentido pós-desenvolvimentista (AcosTA, 2010). A constitucionalização dos "direitos da natureza” prefigurava, mais que qualquer outro elemento, tal horizonte.

A própria Carta Magna deixa entrever, contudo, a complexidade das articulações entre bem viver e desenvolvimento: o artigo 275 define o regime de 
desenvolvimento "como o conjunto de sistemas econômicos, socioculturais e ambientais que garantem a realização do sumak kawsay". Mais que antitéticas, ambas as noções aparecem imbricadas entre si. Além disso, o bem viver também toma a forma de direitos convencionais dentro de um sistema - o "regime do bem viver" -, composto por âmbitos de política pública, como educação, saúde, segurança, lazer, cultura, esportes, ciência, etc. (artigo 340). Tais postulados se materializaram em meio a um intenso conflito no interior da AP. Desde então, emergiram outros focos de protesto que terminaram por colocar a questão do bem viver, o meio ambiente e o modelo de desenvolvimento no centro da luta política.

Assim, desde os dias da ANC, abriu-se uma disputa - dentro e fora da $\mathrm{RCb}$ entre um "polo ambientalista" e um "polo (neo)desenvolvimentista". O primeiro, que misturava frações da AP com organizações indígenas, camponesas e ambientalistas, formulou uma retórica contrária a um padrão de desenvolvimento com base em formas convencionais de exploração dos recursos naturais e pouco sensível ao respeito às formas de vida locais. O polo (neo)desenvolvimentista, em contrapartida, assumiu com realismo a nova etapa econômica e privilegiou a transição pós-neoliberal, em vez da materialização de políticas pós-desenvolvimentistas. Este incluía o uso dos recursos estratégicos do país - sobretudo o petróleo - como base material para financiar tanto a expansão dos direitos promovidos na Carta Magna como a reativação das forças produtivas nacionais. Em outras palavras, priorizava as políticas de desenvolvimento (entre as quais, o extrativismo) como via para a realização do bem viver (em sentido amplo, e não reduzido à "cosmovisão pachamâmica”).

A ascensão política do polo realista - amparado pela postura do próprio presidente - consolidou o trânsito pós-neoliberal e deu continuidade à matriz de acumulação primário-exportadora do país. A mobilização ambientalista não tardou em se desencadear em um sentido que se desdobra entre a prefiguração de uma sociedade que não dependa primordialmente da exploração dos recursos naturais e a defesa das formas de vida locais ameaçadas pelo avanço da fronteira extrativista em certos territórios. A progressiva dissolução da dimensão ambiental do princípio do bem viver e a rearticulação do modelo de desenvolvimento firmemente adotado pela RC aparecem, assim, como a problemática comum a diversos conflitos do período. Em sua confluência se delineia o terceiro CCP analisado.

1. Um primeiro cenário de confrontação, logo após a ANC, foi o despacho da Lei de Mineração. Tratava-se de uma das regulamentações fundamentais da transição pós-constituinte, porque, desde 2007, a atividade mineradora do país se encontrava paralisada pela decisão estatal de reverter 97\% das licenças que haviam 
sido concedidas a empresas privadas em anos anteriores. Em meio ao alto preço internacional dos minérios, o governo buscava reorganizar por completo o setor e, por isso, requeria que essa lei fosse aprovada de forma urgente.

Entretanto, em todo o decorrer do trâmite legislativo, tornou-se evidente a resistência de diversas organizações a uma regulamentação que, segundo elas, concedia à mineração um status de indústria, habilitava explorações em grande escala e debilitava a eficácia dos princípios do bem viver, recém-consagrados no texto constitucional. Assim, sob a convocatória da ConAIE, em janeiro de 2009, registrou-se um levante popular destinado a revogar a votação da lei. Nesse contexto, o Presidente Correa acusou os mobilizados de "fundamentalistas infantis" e sustentou a decisão governamental, afirmando que "o desenvolvimento responsável da mineração é fundamental para o progresso do país [...]”16. O confronto entre o presidente e as coalizões antimineração alcançou níveis inéditos de beligerância.

Em todo o caso, e na contramão do que havia acontecido sob o neoliberalismo, tal regulamentação reposiciona o Estado no setor, criando a Empresa Nacional de Mineração e incrementando sua participação nos lucros da mineração ( $5 \%$ mínimo sobre as vendas e 70\% em impostos sobre rendas extraordinárias). Os representantes da mineração (privada) rechaçaram essa orientação da lei. No que se refere a questões ambientais, o governo defendeu a tese de uma "mineração responsável": a lei plasmou a existência de novos mecanismos de prevenção de impactos, a opção de suspender as concessões em casos de dano ao meio ambiente ou aos direitos humanos e introduziu a figura compulsória da participação e consulta à cidadania, por parte do Estado, no decorrer na exploração mineira (LATORRE, 2012, p. 126-127).

Os detratores dessa regulamentação argumentavam que, apesar do "retorno estatal" ao setor, a lei dava continuidade à política de conceder às empresas transnacionais um status de agentes econômicos nacionais. Isso, no marco da declaração da mineração como atividade de utilidade pública, conferia um tratamento privilegiado às empresas privadas com fins lucrativos e ampliava a possibilidade de violar direitos humanos, direitos coletivos, direitos de acesso à água e também os direitos da natureza (LATORRE, 2012, p. 127-128). Com relação a esse último ponto, as organizações reprovavam a debilidade dos controles ambientais dispostos na lei, assim como o virtual fechamento à participação das comunidades para proteger direitos, ao longo do ciclo de exploração mineira. Essa questão remetia à insatisfação com a Constituição, que não reconheceu a figura do "consentimento prévio".

16 Discurso de Correa perante a legislatura (15 jan. 2009). Consultar: <http://www.presidencia. gob.ec/discursos/>. 
Embora o marco discursivo do protesto antimineração tenha ressaltado os efeitos da mineração sobre o meio ambiente e embora o próprio governo tenha buscado ler tal protesto somente nessa chave - "ecologistas" contra o desenvolvimento -, convém ressaltar que boa parte da disputa está vinculada às qualidades que a dinâmica da mineração adquiriria no Equador pós-constitucional. Os mobilizados resistiam à política de mineração do governo não somente em nome dos direitos da natureza, mas também de seu suposto caráter antinacional e da magnitude das explorações. Nas palavras de Marlon Santi, presidente da ConAIE à época das mobilizações: "Não se pode abrir um projeto de lei para vender a soberania às transnacionais. Mas podemos, sim, no momento atual, regular a mineração atual de tipo artesanal"17. Assim, a defesa da água, da natureza, etc. não foi o único significado da luta contra a Lei de Mineração.

A controvérsia também resvalava na questão da globalidade do modelo de desenvolvimento esboçado pelo governo: a relação entre capitais transnacionais e nacionais, o lugar da economia local (comunitária, artesanal) na reativação produtiva e o caráter mais ou menos participativo do Estado. Não em vão, em meados de 2009, a CoNAIE apresentou um pedido de inconstitucionalidade dessa lei, apresentando como argumento a violação do direito das comunidades à consulta pré-legislativa e à consulta prévia.

2. Uma das iniciativas mais radicais que o governo da RC havia implementado no início de seu primeiro mandato (2007) foi a decisão de não explorar as reservas petrolíferas do Parque Nacional Yasuní, um campo que contém aproximadamente um bilhão de barris de petróleo. Tal decisão foi impulsionada pela ala ambientalista do gabinete de Correa e sempre encontrou opositores em seus setores mais tradicionais. A iniciativa consistia em deixar sob a terra o óleo cru existente no campo petrolífero ITT (Ishpingo-Tambococha-Tiputini) do parque, uma das reservas de biosfera mais importantes do planeta. Procurava-se manter intocadas 20\% das reservas de petróleo, em troca de uma contribuição financeira internacional de $50 \%$ do que o Equador poderia ter ganhado se as explorasse. A outra metade seria assumida pelo país, constituindo-se, assim, no principal fomentador de uma iniciativa global inédita que contribuiria para mitigar os efeitos da mudança climática, para conservar a biodiversidade e para manter o respeito aos povos indígenas que vivem no Parque Nacional (René Ramírez Gallegos, 2012).

17 Consultar: El Tiempo, 1 set. 2009. Disponível em: <http://www.eltiempo.com.ec/noticias-cuenca/8913-indigenas-anuncian-protestas-en-contra-ley-minera/>. Acesso em: 4 de abril de 2015 . 
A iniciativa ITT condensava um dos mais altos princípios do bem viver formulados pela RC. De fato, o discurso oficial vinculou a não exploração do Yasuní com a consolidação dos direitos da natureza e com a busca de formas alternativas de desenvolvimento, como a edificação de uma economia pós-petrolífera (LE QuANG, 2013). Tal projeção aproximava o governo de organizações ecologistas e de outros movimentos.

Não obstante, o caráter bifronte de uma política energética que apostava no fortalecimento da produção petrolífera nacional, ao mesmo tempo em que demandava, da comunidade internacional, contribuir para sustentar no tempo a não exploração do óleo cru, explicava, talvez, por que a iniciativa não mobilizou o apoio explícito de grande parte dos coletivos ecologistas e de outras organizações sociais. O governo promoveu a iniciativa praticamente sozinho. Inclusive seus aliados, em nível regional - os países da AlBA -, olharam com total desdém para essa medida emblemática.

Com isso, em meados de 2013, o presidente anunciou o fim da iniciativa, ressaltando que se tratava de uma decisão dolorosa, mas que devia ser condizente com as necessidades fundamentais que possuem ainda as grandes maiorias. Sua decisão obedecia, de fato, à quase nula contribuição financeira da comunidade internacional: após seis anos de vigência da proposta, não havia sido recolhido nem $3 \%$ do valor esperado. A decisão significava um golpe para a ala "programática" - mais à esquerda - do governo, que tinha feito do ITT um ícone da mudança na matriz produtiva e do bem viver. A iniciativa também foi assim considerada por amplos setores sociais que ainda não haviam se mobilizado diretamente pela causa e, embora mantivessem uma relação tensa com o governo, sempre respaldaram a opção de deixar "o óleo cru embaixo da terra".

A decisão presidencial ativou a mobilização de cidadãos das classes médias, coletivos ecologistas, jovens universitários, certas organizações camponesas e indígenas e outras de tipos distintos (inclusive afins à RC). Embora não tivessem grande apoio popular nem um caráter massivo, os protestos persistiram - sobretudo em Quito - até maio de 2014. Diante de tal cenário, Correa seguiu seu roteiro de desconhecimento dos atores em conflito, embora suas demandas não fizessem mais que retomar o discurso que o próprio governo havia sustentado desde o começo. Não houve a mínima abertura aos mobilizados, que, além do mais, apresentavam algumas alternativas para alcançar as cotas de financiamento público que a exploração do ITT traria ao fisco. A propaganda oficial simplesmente colocou suas demandas como antípodas ao projeto nacional de combater a pobreza e alcançar o desenvolvimento - que foram os argumentos com os quais Correa 
guarneceu sua decisão de não continuar com a iniciativa ${ }^{18}$. Diante do fechamento do espaço político, cresceram as vozes a favor da participação cidadã para dirimir a exploração de petróleo no ITT. Começou, assim, um processo de coleta de assinaturas - liderado por coletivos com alto protagonismo juvenil (em particular, a organização não governamental YASUNIDOS) - para convocar uma consulta popular sobre a conveniência ou não da exploração petrolífera. Embora tal objetivo tenha sido alcançado, o Conselho Nacional Eleitoral, após um obscuro processo de verificação, invalidou 60\% das assinaturas, por vícios de procedimento. Amplificou-se, então, a sensação do caráter inconsulto de uma decisão que o próprio governo havia construído como marca de sua identidade revolucionária.

Definitivamente, ao longo do mandato de Correa, emerge um CCP ao redor dos sentidos do bem viver e do desenvolvimento. Diversas mobilizações colocam a continuidade da matriz extrativista como uma situação problemática para o prolongamento indefinido de todas as formas de vida, a construção do Estado plurinacional e a implantação de um processo econômico soberano e alternativo (pós-desenvolvimentista, pós-capitalista). Tal conflitividade, ainda em plena gestação, aparece como o correlato de uma das contradições constitutivas do processo de mudança em curso: a tensão entre o relançamento de um Estado orientado a proteger uma carta ampla de direitos cidadãos e as regulações para o uso dos recursos naturais que estão na base das capacidades de acumulação e redistribuição do Estado (sem as quais não se pode garantir, a curto e médio prazos, o cumprimento dos direitos).

\section{BREVE CONCLUSÃO}

Os três espaços de luta analisados parecem dar conta da pertinência de uma perspectiva em que a articulação entre conflitos políticos e problemas públicos captura um dos efeitos da atividade dos movimentos sociais. Assim, durante os governos da RC, foi possível identificar como, em meio à fragilidade do tecido social, diversos atores sociais contribuem para delinear as querelas sociais que conferem as coordenadas fundamentais da disputa democrática.

18 Apesar do bom momento da economia equatoriana até 2014, durante o ciclo de governo aberto em 2013, as necessidades fiscais cresceram na esteira da aposta por mudar a matriz produtiva (megainvestimentos públicos em refinarias e hidrelétricas). A decisão de explorar o ITT está ligada a tal problemática. Anos atrás, diversos setores ecologistas já haviam se pronunciado contra a ideia de financiar a reconversão produtiva com os recursos provenientes da mineração - "extrativismo para sair do extrativismo". O fato é que os investimentos na mineração também não começaram agora e, já em 2013, o presidente viu a necessidade de ampliar a fronteira petrolífera até o parque Yasuní. 
De fato, as lutas por reconhecimento, legitimidade da representação social nas instituições públicas e religação entre bem viver e desenvolvimento, durante a transição pós-neoliberal no Equador do século XXI, jogam luzes sobre o potencial de expansão e conexão de lutas que aparecem, a priori, fragmentadas. Tal expansão é pensada a partir da dimensão normativa do conflito, ou seja, aquela que alude ao registro do universal contido em episódios contenciosos específicos. Ao insistir na ideia de problemas comuns, a abordagem dos CCP tem, portanto, a vantagem de examinar as passagens do particular ao geral, a partir de uma perspectiva que insiste na face antagônica e no caráter processual da política.

Os três CCP estudados fornecem elementos para compreender interações socioestatais específicas e alguns elementos que caracterizam o processo político em curso. Apesar de sua relativa incapacidade de interlocução com os atores organizados, o governo da RC teve de entrar no jogo para (re)definir os problemas públicos instalados "desde abajo" no espaço político. Isso mostra a conexão entre os CCP e os sentidos da luta hegemônica.

Com relação a esse último ponto, a abordagem proposta permite identificar pelo menos dois desafios do processo de mudança iniciado em 2007. Por um lado, continuar ampliando a margem de autonomia relativa do Estado para consolidar as políticas pós-neoliberais e promover uma agenda que garanta a universalização dos direitos. Ao mesmo tempo, reabrir o jogo político à sociedade, a fim de estender as próprias bases e fronteiras do projeto político. Isso, no entanto, mostra-se improvável, porque a política presidencial não confere sinais de valorização da centralidade da participação e interlocução com a pluralidade do social. $\mathrm{O}$ retrocesso hegemônico pode, nesse sentido, acelerar a conflitividade (ainda) sem sujeitos que a encarnem e, ao mesmo tempo, desgastar a própria legitimidade da Revolução Cidadã.

\section{REFERÊNCIAS BIBLIOGRÁFICAS}

Acosta, Alberto. El buen vivir en el camino del post-desarrollo una lectura desde la Constitución de Montecristi. FES-ILDIS: Quito, 2010.

CEFAï, Daniel. Investigar los problemas públicos con y más allá de Joseph Gusfield. In: Gusfield, Joseph. La cultura de los problemas públicos. El mito del conductor alcoholizado versus la sociedad inocente. Buenos Aires: Siglo Veintiuno Editores, 2014.

CEFAI, Daniel; Trom, Danny. Les formes de l'action collective. Mobilisations dans des arènes publiques. Paris: École des Hautes Etudes en Sciences Sociales, 2010. 
Chávez, David. Consulta previa en el Ecuador. Quito: CDEs, 2010.

Constitución de la República del Ecuador. Quito, Equador, 2008

Gusfield, Joseph. La cultura de los problemas públicos. El mito del conductor alcoholizado versus la sociedad inocente. Buenos Aires: Siglo Veintiuno Editores, 2014.

Honneth, Axel. El reconocimiento como ideología. Isegoría, n. 35, p. 129-150, 2006.

LATORRE, Laura Tomas. El movimiento ecologista popular anti-minero en el Ecuador. CAAP, Quito, p. 123-145, 2012.

LE Quang, Matthieu. Dejar el petróleo bajo tierra. La iniciativa Yasuní ITT. Quito: Iaen, 2013.

Ley Orgánica de Servicio Público (Losep). QUiTO, Equador, 2010. Disponível em: <http:// www.finanzas.gob.ec/wp-content/uploads/downloads/2012/o9/reglamento_ley_ servicio_publico.pdf $>$. Acesso em: 15 de abril de 2015 .

Neveu, Eric. Sociología de los movimientos sociales. Quito: Abya Yala, 2000.

O’Donnell, Guillermo; OszLak, Oscar. Estado y políticas estatales en América Latina: hacia una estrategia de investigación. Revista Redes, p. 99-128, 1987.

Ospina, Pablo. Corporativismo, estado y revolución ciudadana. El Ecuador de Rafael Correa. In: Büschges, Christian; Kaltmeier, Olaf; Sebastian, Thies (Ed.). Culturas políticas en la región andina. Madrid-Frankfurt: Iberoamericana/Vervuert, 2011.

Periódico el Universo. GUAYAQUIL, Equador, 11 de outubro de 2009.

Posso, Carlos. El retorno de Ulises. Estado y participación política: conflicto UNE/ Gobierno. 169 p. 2013. Tese (Mestrado em Ciências Políticas) - Flacso-Ecuador, Quito, 2013.

Ramírez Gallegos, Franklin. La insurrección de Abril no fue sólo una fiesta. Quito: Taller el colectivo, 2005.

Postneoliberalismo indócil. Agenda pública y relaciones socio-estatales en el Ecuador de la Revolución Ciudadana. Revista Temas y Debates, n. 20, 2010a.

Fragmentación, reflujo y desconcierto. Movimientos sociales y cambio político en el Ecuador (2000-2010). Revista OSAL, n. 28, p. 17-47, 2010 .

. Despliegues de la autonomía estatal en el Ecuador de la Revolución Ciudadana. Debates y Combates, n. 4, nov.-dez. 2012.

Ramírez Gallegos, Franklin et al. Nuda política. Democracia, participación y conflictos sociales en el Ecuador (2009-2012). Quito: ILdIS-FLACSO-Perfiles de Opinión, 2013a. . Coaliciones parlamentarias y conflictividad social en el Ecuador. La política de la transición post-constituyente (2009-2011). Quito: ANE, 2013b.

Ramírez Gallegos, Franklin; Stoessel, Soledad. Postneoliberalismo, cambio y conflicto político en el Ecuador de la Revolución Ciudadana. In: Argento, Melisa; Ciccone, Ana 
Laura (Coord.). Pulsión de cambio: movimiento latinoamericano en la construcción de proyectos contra-hegemónicos. Rosario: Editorial Último Recurso, 2015.

RAMírez GALLEGos, René. Una gran transición para una gran transformación. Reflexiones a partir de la iniciativa Yasuní-ITT. In: Blackburn, R.; Fraser, N.; Therborn, Goran; Ramírez Gallegos, R. Nuevas fronteras de la izquierda. Quito: Iaen, 2012.

Ramírez Gallegos, René; Minteguiaga, Analía. Transformaciones en la educación superior ecuatoriana: antecedentes y perspectivas futuras como consecuencias de la nueva constitución política. Educación Superior y Sociedad, v. 15, n. 1, 2010.

Revista Ecuador Debate. CaAp, Quito, Série 1983-2010.

SEnPlades. Plan Nacional de Desarrollo (2007-2010). Quito, Ecuador. Disponível em: $<$ http://www.planificacion.gob.ec/plan-nacional-de-desarrollo-2007-2010/>. Acesso em: 10 de abril de 2015.

Schillagi, Carolina. Problemas públicos, casos resonantes y escándalos. Polis, n. 30, 2011. STOESSEL, Soledad. Políticas y conflicto político durante el post-neoliberalismo: el caso del 30-S en Ecuador. Revista Perspectivas de Políticas Públicas, Universidad Nacional de Lanús, 2013a.

Conflictos políticos y gobiernos post-neoliberales. Los casos de Argentina y Ecuador en tiempos de retorno estatal. Tese (Mestrado em Ciências Políticas) FLACSO-Ecuador, Quito, 2013b.

Tilly, Charles. Conflicto político y cambio social. In: Güell, Pedro Ibarra; MontaÑa, Benjamín Tejerina (Ed.). Los movimientos sociales. Transformaciones políticas y cambio cultural. Madri: Trotta, 1998. 